\title{
Transient psychological syndrome following diazepam therapy for tetanus
}

\author{
J. MalatinskÝ \\ M.D.
}

\author{
M. ProcházKa \\ M.D., C.Sc.
}

\author{
T. KADLIC \\ M.D.
}




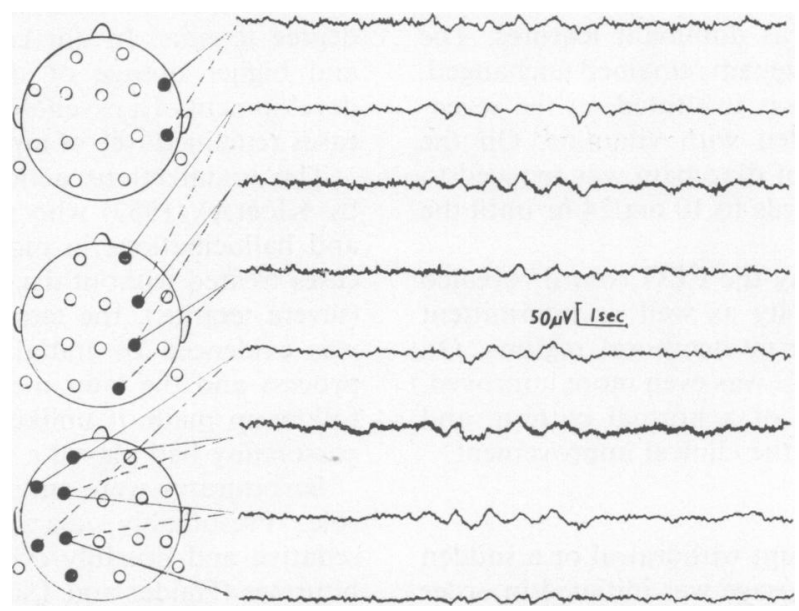

FIG. 1 Irregular background activity of lower amplitude, involving some dispersed theta waves. Bursts of delta waves bilaterally, predominantly in anterior regions.

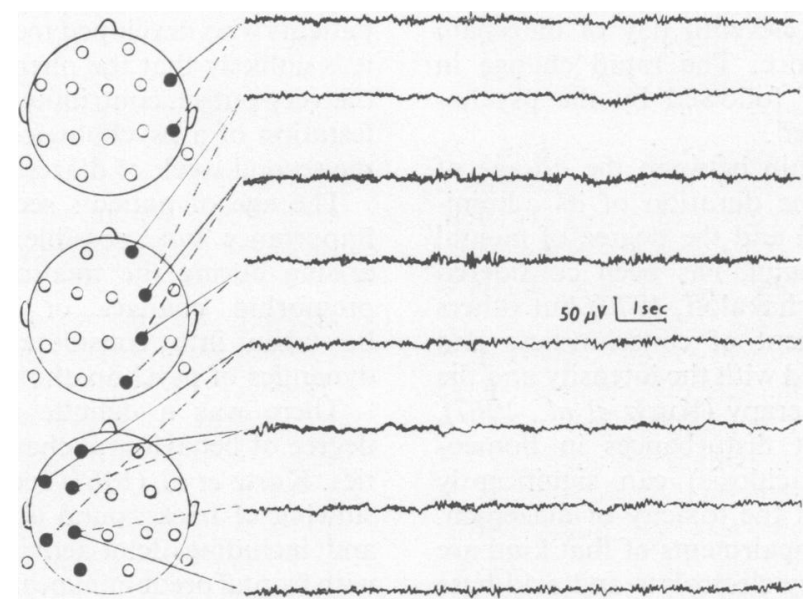

FIG. 2. Generalized fast activity as a dominant feature. The bursts of delta waves disappeared.

persisted. The psychomotor restlessness disappeared. The normalization of mental state progressed further, and 2 weeks after the drug was stopped no mental abnormalities were present at all. The EEG correlated with the clinical improvement and at that time the EEG tracing was at the borderline of normal (Fig. 2).

\section{Case 2}

A 60 -year-old man suffering from severe tetanus was admitted to the I.C.U. Diazepam therapy was commenced on admission and continued for 34 days, the total dose amounting to $4570 \mathrm{mg}$. Except for the first i.v. dose it was given orally in an average daily dose of $134 \mathrm{mg}$. In addition, during the first 3 days pentobarbitone $300 \mathrm{mg} / 24 \mathrm{hr}$ was given orally. During these days, while the patient breathed ${ }^{N}$ spontaneously, psychic retardation was revealed. N Then the patient had to be tracheostomized, paralysed 0 with pancuronium and ventilated artificially for 180 days in total. On terminating the period of muscle $\widetilde{\Phi}$ paralysis he was able to obey verbal commands. On ? the 11 th day the dosage was suddenly reduced from 0 $120 \mathrm{mg} / 24 \mathrm{hr}$ to $30 \mathrm{mg} / 24 \mathrm{hr}$. The change resulted in $\mathrm{a} \underset{\mathbb{D}}{\mathrm{d}}$ 
psychological and behavioural syndrome, with negativism and mutism as dominant features. The daily dosage of $30 \mathrm{mg}$ diazepam remained unchanged. Therapy with pyritinol was instituted on the seventeenth day and supported with vitamins. On the twentieth day, the dose of diazepam was reduced to $20 \mathrm{mg} / 24 \mathrm{hr}$ and afterwards to $10 \mathrm{mg} / 24 \mathrm{hr}$ until the thirty-fourth day.

On the twenty-fifth day the EEG record revealed a generalized slow activity as well as intermittent delta rhythm in both frontotemporal regions. On the thirty-eighth day EEG was even more improved, attaining the borderline of a normal pattern, and corresponding well with the clinical improvement.

\section{Discussion}

In our patients an abrupt withdrawal or a sudden reduction of diazepam dosage was initiated in order to obtain clear information on the actual clinical state (muscular rigidity, tendency to spasms, level of consciousness). Thus, in Case 1 the drug was suddenly withdrawn from $80 \mathrm{mg} / 24 \mathrm{hr}$ and in Case 2 the dosage was abruptly reduced from $120 \mathrm{mg} / 24 \mathrm{hr}$ to $30 \mathrm{mg} / 24 \mathrm{hr}$, on the eleventh day of diazepam treatment in each instance. The rapid change in dosage was immediately followed by the psychological syndrome described.

The possible relationship between the dosage of diazepam and/or the time duration of its administration on the one hand and the degree of mental disorder on the other hand, has been considered unlikely (Haider and Tschakaloff, 1970) but others found that the impairment of consciousness and EEG alterations are linked with the intensity and the duration of diazepam therapy (Kurtz et al., 1967). Milne (1965) states that disturbances in homeostasis of body fluids (acidosis) can significantly influence the efficacy and the toxicity of diazepam. In our cases, however, impairments of that kind are out of the question as any electrolyte and acid-base shifts were corrected immediately.

The tetanus toxin, fixed as it is to nervous tissue (cellular lipoid components, ganglioside and cerebroside), is known to play an important role in damaging the central nervous tissues (Frank, 1956). In particular, ganglioside is accumulated at sites of action of tetanus toxin, i.e. at the synaptic membranes. The high affinity of the drug to lipoid tissues (Van der Kleijn, 1969) seems to conform with the Kendall and Clarke case of delayed regaining of consciousness in an obese patient treated with large doses of diazepam for tetanus; this was accounted for by the cumulative body stores (Kendall and Clarke, 1972).

Mental disorders occur rather with severe and moderate tetanus, than with milder degrees. However, Haider and Tschakaloff (1970), classifying tetanus patients in five degrees, observed confusion and paranoid-hallucinatory picture even with second degree tetanus. In our cases, more severe degrees and higher dosage of diazepam have led to the development of a psychological syndrome, while mild cases remained free of any psychiatric alterations.

The toxinfectious aetiology has been supported by Kloetzel (1963) who reported on disorientation and hallucinations in moderate and severe tetanus cases treated without diazepam. Even in our Case 2 (severe tetanus), the tetanus toxipathic component was evidenced by initial slowing of psychological process and the later mental normalization during follow-up made it unlikely that altered premorbid personality had played a role.

Barbiturates were supposed to play an adjuvant role. Presumably, diazepam may potentiate the sedative and possibly even the side effects of barbiturates (Haider and Tschakaloff, 1970). Nevertheless, Kurtz et al. (1967) found no influence of barbiturates on EEG pattern and ascribed all changes to diazepam. Femi-Pearse (1966), treating patients with diazepam and/or barbiturates, failed to discriminate between these two dosages in respect of patients who developed mental changes. In our cases, it is unlikely that the phenobarbitone, given only at the very outset, contributed significantly to the manir festation of a psychological syndrome at the end of the second week of diazepam therapy.

The age of patients seems not to be of decisive importance but, possible hypoxic cerebral lesions arising during the treatment, as well as potential premorbid changes of personality should also be taken into consideration when assessing the dynamics of psychopathology.

There was a definite relationship between the degree of behavioural changes and EEG abnormalities. Kurtz et al. (1967) found changes ranging from slowing of background activity to periodic silences and including delta-activity, either generalized, or with frontal predominance, unstable, often associated with fast rhythms and with unreactive 10-12 c/sec activity. In the present cases, EEG records correlated well with the clinical course and the abnormal EEG pattern improved in parallel with the normalization of mental disorders. The EEG findings are not specific, but are similar to those described with alcohol and drug withdrawal syndromes (Penin, 1971).

Thus, 'withdrawal symptoms' following a longterm diazepam treatment with high doses in tetanus in fact signify a psychological syndrome of complex aetiology, the abrupt withdrawal of the drug being only a precipitating factor leading to cerebral decompensation (Haider and Tschakaloff, 1970).

Psychiatric symptoms in our patients occurring on withdrawal have been suppressed efficiently by a short-term reinstitution of diazepam in low doses 
(10-30 $\mathrm{mg} / 24 \mathrm{hr}$ ). The disappearance of mental disorder was accelerated by regulators of cerebral metabolism and vitamins.

\section{Acknowledgment}

We are indebted to $\operatorname{Dr} Z$. Luptáková for her psychiatric care of out tetanus patients.

\section{References}

Femi-Pearse, D. (1966) Experience with diazepam in tetanus. British Medical Journal, 2, 862.

FranK, M. (1956) Die Erfolgsaussichten bei der Behandlung des schweren Tetanus. Archiv für klinische Chirurgie, 284, 149.

Haider, W. \& Tschakaloff, Ch. (1970) Passagere psychische Nachwirkungen bei Langzeitbehandlung des Tetanus mit Diazepam (ValiumR). Anaesthesist, 19, 165.

Kendall, M.J. \& Clarke, S.W. (1972) Prolonged coma after tetanus. British Medical Journal, 1, 354.
Kloetzel, K. (1963) Clinical patterns in severe tetanus. Journal of the American Medical Association, 185, 559.

Kurtz, D., Tempe, J.D., Feuerstein, J., Reeb, M. \& Mantz, J.M. (1967) Clinical and EEG changes in tetanus during intensive and prolonged treatment with diazepam. Electroencephalography and Clinical Neurophysiology, 23, 582.

MiLne, M.D. (1965) Influence of acid-base balance on efficacy and toxicity of drugs. Proceedings of the Royal Society of Medicine, 58 (suppl.), 961.

Penin, H. (1971) Das EEG der symptomatischen Psychosen. Nervenarzt, 42, 242.

ReLkiN, R. (1966) Death following withdrawal of diazepam. New York State Journal of Medicine, 66, 1770.

Rollason, W.N. (1968) Diazepam as an intravenous induction agent for general anaesthesia. In: Diazepam in Anaesthesia (Ed. by P. F. Knight and C. G. Burgess), p. 70. Wright, Bristol.

Van Der Kleisn, E. (1969) Kinetics of distribution and metabolism of diazepam in animals and humans. Archives internationales de pharmacodynamie et de thérapie, 182, 433. 